\title{
MÚSICA NA ESCOLA: proposta de intervenção em escolas de ensino médio em São Luís-MA
}

\author{
MUSIC INTO SCHOOL: Proposal for intervention in high schools in São Luís-MA \\ MÚSICA EN LA ESCUELA: propuesta de intervención en escuelas de enseñanza media \\ en São Luís-MA
}

\begin{abstract}
João Fortunato Soares de Quadros Júnior Professor Doutor do Departamento de Artes e do Mestrado Profissional em Gestão de Ensino da Educação Básica da Universidade Federal do Maranhão (UFMA). São Luís-MA, Brasil. joaofjr@gmail.com

Oswaldo Lorenzo Quiles Professor Doutor da Universidad de Granada (UGR). Melilla, Espanha. oswaldo@ugr.es

Mara Rachel Souza Soares de Quadros Doutoranda em Ciências da Educação pela Universidade de Granada (UGR). Granada, Espanha. mararachel@gmail.com
\end{abstract}

Ana Déborah Pereira de Barros Mestranda no Programa de Gestão de Ensino da Educação Básica da Universidade Federal do Maranhão (UFMA).

São Luís-MA, Brasil. anadeborahbarros@gmail.com

\begin{abstract}
RESUMO: Esse estudo teve como objetivo implementar um plano de ações para a inclusão da Música no ensino médio em São Luís/MA. Para tanto, buscamos elaborar uma proposta curricular adequada à legislação e aos documentos norteadores da educação, tanto em âmbito nacional como local. Além disso, o trabalho propôs também a elaboração de materiais didáticos para o ensino de Música direcionado ao ensino médio, a partir da consulta a materiais didáticos já existentes e em conformidade com o previsto nas Diretrizes Curriculares da SEDUC-MA. Dessa forma, a pesquisa empregou um desenho de pesquisa quase-experimental, contando com a participação de 10 escolas públicas, contemplando aproximadamente 1000 alunos. Para coleta de dados, utilizou-se da aplicação de questionários para diagnóstico das turmas e avaliação da proposta desenvolvida, reuniões pedagógicas e relatórios dos professores. Assim, esse trabalho conseguiu obter as seguintes conclusões: 1) a proposta desenvolvida obteve a aprovação dos participantes; 2) os estudantes de ensino médio são favoráveis à inserção da Música enquanto disciplina do currículo escolar; 3) fatores como infraestrutura, água e segurança influem diretamente no desenvolvimento da educação. Dessa forma, espera-se que esse estudo possa contribuir para o surgimento de propostas similares em outras localidades do país. PALAVRAS-CHAVE: Música. Ensino médio. Adolescentes. Currículo. Brasil.
\end{abstract}

ABSTRACT: This study aims to implement an action plan to include Music in high school in São Luis/MA. For this end, it was elaborated a curricular proposal according to the current legislation and documents that guides the educational system, in both local and national context. In addition, this work proposed the elaboration of material to music teaching appropriated to high school through searching of existent materials and according to the Curricular Guidelines of SEDUC - MA. Thus, this research used a quasi-experimental design and had the participation of 10 public schools, including around 1000 students. To data collection, it was used bibliographic and documental research, questionnaires to the group diagnostics and evaluations of the developed proposal, week meetings, and teachers' reportings. As conclusion, this work obtains the following results: 1) The developed proposal obtained the approval of the participants; 2) high school students were favorable to the insertion of Music as a discipline of the school curriculum; 3) factors such as infrastructure, water, and safety influence directly to the educational development. Thus, it is expected that this study may contribute to the emergence of similar proposals in other localities of the country. KEYWORDS: Music. High school. Teenagers. Curriculum. Brazil.

Artigo recebido em maio de 2017

Aprovado em julho de 2017 
RESUMEN: Este estudio tuvo como objetivo implementar un plan de acciones para inclusión de la Música en la enseñanza media en São Luís/MA. Para tanto, buscamos elaborar una propuesta curricular adecuada a la legislación y a los documentos oficiales de la educación brasileña, tanto en ámbito nacional como local. Además, el trabajo propuso también la elaboración de materiales didácticos para la enseñanza de Música dirigida a la enseñanza media, a partir de la consulta a materiales ya existentes y en conformidad con lo previsto en las Directrices Curriculares de SEDUC-MA. De esa forma, la investigación empleó un diseño de investigación casi-experimental y contó con la participación de 10 escuelas públicas, abarcando aproximadamente 1000 estudiantes. Para la recopilación de datos, se ha utilizado cuestionarios para diagnóstico de los participantes y evaluación de la propuesta desarrollada, encuentros pedagógicos e informes de los maestros. Así, este trabajo logró obtener las siguientes conclusiones:1) la propuesta desarrollada obtuvo la aprobación de los participantes; 2) los estudiantes de la enseñanza media son favorables a la inclusión de la Música cómo asignatura del currículo escolar; 3) factores como infraestructura, agua y seguridad influyen directamente en el desarrollo de la educación. De este modo, logramos que ese estudio pueda contribuir para el surgimiento de propuestas similares en otras localidades del país.

PALABRAS CLAVE: Música. Enseñanza Media. Adolescentes. Currículo. Brasil. 
MÚSICA NA ESCOLA | João F. S. de Quadros Júnior et. al.

\section{1| INTRODUÇÃO}

O presente artigo tem como objetivo relatar e avaliar um estudo desenvolvido com alunos de ensino médio de escolas públicas em São Luís/MA na qual foram oferecidas aulas de Música dentro do currículo escolar. Dessa maneira, esse trabalho vem propor uma reformulação do currículo atual do ensino médio ao sugerir a inclusão da Música não apenas como conteúdo do componente curricular Arte, como preconiza a Lei $n^{\circ} 13.278 / 16$, mas sim enquanto disciplina propriamente estabelecida, lecionada por docentes com formação específica na área.

Inicialmente, faz-se necessário refletir sobre o conceito e a empregabilidade do termo currículo. Etimologicamente, esse termo designa percurso, trajetória, caminho (LIBÂNEO, 2004). O currículo encerra, de modo geral, duas perspectivas: uma enquanto estrutura de conhecimentos historicamente acumulados que devem ser assimilados de maneira passiva pelo estudante; e a outra, como um conjunto de saberes e experiências vivenciadas ativamente pelos alunos (GOODSON, 2005).

O currículo não é um programa totalmente previsto ou prescritivo (PACHECO, 2005), mas um projeto de construção e de intervenção na realidade como forma de melhorá-la, atribuindo ao professor uma posição de gestor do currículo (LEITE, 2000). Desse modo, podemos afirmar que o currículo não é estático, já que o mesmo deve ser elaborado considerando as demandas sociais: "o currículo não pode ser separado do contexto social, uma vez que ele é historicamente situado e culturalmente determinado" (VEIGA, 2007, p. 27). Além disso, Pacheco (1996, p. 18) chama a atenção para outros dois aspectos: a neutralidade e a intencionalidade do currículo.

O currículo é um propósito que não é neutro em termos de informação, já que esta deriva de diferentes níveis e é veiculada por diversos agentes curriculares dentro do contexto de vários condicionalismos. Assim, o currículo corresponde a um conjunto de intenções, situadas no continuum que vai da máxima generalidade à máxima concretização, traduzidas por uma relação de comunicação que veicula significados social e historicamente válidos.

Autores como Libâneo (2004) destaca a existência de três níveis de currículo: 1) currículo formal, que compõe as diretrizes normativas prescritas institucionalmente; 2) currículo real, que diz respeito ao que ocorre efetivamente em sala de aula, como implicação do projeto pedagógico e dos planos de ensino; 3) e o currículo oculto que:

Representa tudo o que os alunos aprendem pela convivência espontânea em meio às várias práticas, atitudes, comportamentos, gestos, percepções, que vigoram no meio social e escolar. O currículo está "oculto" porque ele não é prescrito, não aparece no planejamento, embora se constitua como importante fator de aprendizagem. (LIBÂNEO, 2004, p. 172).

Com base na ideia desse autor, e fazendo relação com o objeto dessa pesquisa, é possível afirmar que a música sempre esteve presente na escola (em especial no ensino médio), não necessariamente de forma explícita (currículos formal ou real), mas sobretudo dentro do currículo oculto. Sua presença é observada cotidianamente nas práticas informais que acontecem nas escolas, nas relações interpessoais que ocorrem dentro e fora das salas de aula, como instrumento facilitador para o aprendizado de outras disciplinas (cantigas/paródias sobre leis da física, fórmulas matemáticas, etc.) e também de modo interdisciplinar, a partir de conexões com outros campos de conhecimento (português, inglês, história, etc.). Apesar de sua reconhecida importância como prática informal, a música possui ainda um espaço bastante reduzido no currículo formal das instituições educacionais brasileiras, sobretudo no que diz respeito ao ensino médio (foco principal desse trabalho), que será melhor explorado na continuação deste trabalho. 
MÚSICA NA ESCOLA | João F. S. de Quadros Júnior et. al.

\section{2 | MÚSICA NA EDUCAÇÃO BÁSICA}

A Música surge como disciplina oficial do currículo escolar brasileiro ainda no Império, a partir do Decreto $\mathrm{n}^{\circ}$ 1.331-A, de 1854, permanecendo assim até implantação da Lei de Diretrizes e Bases da Educação Nacional (LDB) n 5.692/71, legislação esta responsável por englobar todas as linguagens artísticas dentro da atividade Educação Artística (de caráter facultativo em muitas escolas), tendo como ênfase mais recorrente as Artes Plásticas (BARBOSA, 1989; PENNA, 2004; QUADROS JR.; QUILES; 2012). Desde então, a música (enquanto disciplina) permaneceu afastada da maior parte das escolas de educação básica, em especial aquelas distantes dos grandes centros urbanos.

A LDB n ${ }^{\circ}$ 9.394/96 não trouxe novidades de impacto direto para a área musical, porém tornou a Arte (não mais Educação Artística) um componente obrigatório do currículo escolar. A publicação das Diretrizes Curriculares Nacionais dos Cursos de Graduação de cada linguagem artística a partir de 2004 e o surgimento de diversos cursos EaD dessas linguagens vieram fortalecer a luta pela extinção da figura do professor polivalente, oportunizando que cada docente centrasse o seu trabalho no campo em que possui maior domínio/afinidade (Artes Visuais, Artes Cênicas, Dança ou Música).

Essas mudanças, conjuntamente aos debates e movimentos coordenados pelo Grupo de Articulação Parlamentar Pró-Música (GAP) - o qual congregava vários segmentos da sociedade brasileira, especialmente músicos profissionais e associações como a ANPPOM ${ }^{1}$, a $\mathrm{ABEM}^{2}$ e outras - possibilitaram vislumbrar um espaço específico para a Música no currículo escolar. Com isso, foi publicado em 2008 a Lei $n^{\circ} 11.769$ (que foi posteriormente substituída pela Lei $n^{\circ}$ 13.278/16), alterando a LDB vigente, tornando a Música um conteúdo obrigatório do componente Arte nos diversos níveis da educação básica, tanto para a rede pública quanto para a privada, estabelecendo 3 (três) anos para que as instituições se adaptassem às exigências da Lei (BRASIL, 2008).

Um levantamento interessante realizado ao final do prazo estabelecido pela legislação foi o de Jordão et al. (2012), que consultaram todas as 27 Secretarias Estaduais de Educação sobre as mudanças efetivadas acerca do ensino de Música. Dentre as respostas obtidas, pode-se observar que a grande maioria das Secretarias buscaram atender às exigências legais incluindo a Música no currículo escolar enquanto conteúdo da disciplina Arte (provavelmente lecionada de forma polivalente), sendo também oferecida por meio de diferentes projetos extracurriculares, muitos deles vinculados aos programas "Mais Educação" ou "Escola Aberta".

Por outro lado, existem no Brasil algumas iniciativas em âmbito municipal que demonstram uma outra interpretação para essa legislação, entendendo a necessidade de oferecer a Música não como um conteúdo, mas sim como uma disciplina. Como exemplos, podemos citar as propostas desenvolvidas em Porto Alegre/RS (WOLFFENBÜTTEL, 2009), Vitória/ES (FIGUEIREDO; ALBERTI, 2009), Mogi das Cruzes/SP (FERNANDES, 2011) e Natal/RN (MENDES; CARVALHO, 2012), direcionadas sobretudo ao ensino fundamental. Essas cidades investiram na realização de concursos públicos para contratação de professores com formação específica em Música, na oferta de formação continuada para professores de outras linguagens que já atuavam nas redes e também na elaboração de materiais didáticos e de propostas curriculares adequados a cada contexto.

$\mathrm{Na}$ ótica de Mendes e Carvalho (2012), a implementação efetiva da Música na escola depende de três níveis de ações:

\footnotetext{
${ }^{1}$ Associação Nacional de Pesquisa e Pós-Graduação em Música.

${ }^{2}$ Associação Brasileira de Educação Musical.
} 
Políticas: criação de documentos legais como legislações, resoluções e portarias que garantam a inserção da Música nas escolas;

Acadêmicas: promoção de reflexões e debates acerca da relevância da Música na formação humana e, consequentemente, sobre sua inserção no currículo escolar, bem como incentivar a criação de materiais didáticos que instrumentalizem o professor da educação básica na ministração das suas aulas;

Práticas: preparação de professores de Música comprometidos e conscientes do seu papel na educação escolar.

Com relação às ações políticas, vale destacar que além das Leis n 11.769/08 e n 13.278/16 foram publicadas em 2016 as Diretrizes Nacionais para Operacionalização do Ensino de Música, um documento do Ministério da Educação que abrange todos os níveis de ensino e define as obrigações de cada instituição educacional no processo de implementação da Música na escola. Nesse documento fica definido que (BRASIL, 2016b, p. 42) :

$\S 1^{\circ}$ - Compete às escolas:

I - incluir o ensino de Música nos seus projetos político-pedagógicos como conteúdo curricular obrigatório [...];

II - criar ou adequar tempos e espaços para o ensino de Música [...];

IV - organizar seus quadros de profissionais da educação com professores licenciados em Música [...];

$\mathrm{V}$ - promover a formação continuada de seus professores no âmbito da jornada de trabalho desses profissionais;

VII - desenvolver projetos e ações como complemento das atividades letivas [...].

$\S 2^{\circ}$ - Compete às Secretarias:

II - promover cursos de formação continuada sobre o ensino de Música [...];

III - apoiar a formação dos professores e dos demais profissionais da educação em cursos de segunda licenciatura em Música;

V - promover a elaboração, a publicação e a distribuição de materiais didáticos adequados ao ensino de Música nas escolas [...];

VI - realizar concursos específicos para a contratação de professores licenciados em Música;

VIII - viabilizar a criação de Escolas de Música [...].

$\S 3^{\circ}$ - Compete às instituições formadoras de Ensino Superior e de Educação Profissional: I - ampliar a oferta de cursos de licenciatura em Música em todo território nacional [...];

II - inclui nos currículos dos cursos de Pedagogia o ensino de Música;

IV - ofertar cursos de formação continuada para professores licenciados em Música e Pedagogia.

$\S 4^{\circ}$ - Compete ao Ministério da Educação:

I - apoiar técnica e financeiramente os sistemas de ensino para a implementação do ensino de Música nas escolas públicas de Educação Básica;

II - estimular a oferta de cursos de licenciatura em Música [...];

III - estimular a oferta de cursos de formação inicial e continuada na área do ensino de Música [...].

$\S 5^{\circ}$ - Compete aos Conselhos de Educação:

I - definir normas complementares a essas Diretrizes [...];

II - realizar o acompanhamento dos Planos Estaduais, Distritais e Municipais quanto à avaliação da implementação das políticas públicas concernentes ao ensino de Música na Educação Básica. 
Esse documento é considerado pela área da Educação Musical como um importante avanço no tocante à organização do processo de inclusão da Música na escola, uma vez que define de maneira explícita as obrigações de cada instituição educacional. Assim sendo, cabe agora que estas instituições exerçam com responsabilidade o papel que lhes compete, em especial os Conselhos de Educação, no que se refere ao acompanhamento em níveis estadual, distrital e municipal sobre o cumprimento da legislação.

Com relação às ações acadêmicas, é relevante ressaltar que todos os 27 estados possuem cursos de licenciatura em Música na modalidade presencial, congregando mais de 150 cursos no Brasil (QUEIROZ, 2016). Entretanto, ainda são poucas as universidades públicas que oferecem esse curso na modalidade $\mathrm{EaD}^{3}$, com destaque para a UFRGS, a UFSCar e a UnB. Existem também universidades que vem oferecendo essa formação como segunda licenciatura, especialmente através do Plano Nacional de Formação de Professores de Educação Básica - PARFOR ${ }^{4}$ (FIALHO, 2015).

Ainda sobre as ações acadêmicas, a publicação da Lei $n^{\circ} 11.769 / 08$ e as diversas ações levadas a cabo em âmbito municipal (como as mencionadas anteriormente) fizeram com que se verificasse também um aumento considerável no quantitativo de publicações (pesquisas e materiais didáticos) para o ensino de música na educação básica, em especial para a educação infantil e o ensino fundamental. Em contrapartida, não foi observado o mesmo avanço nesse quesito para o ensino médio, demandando por isso uma atenção especial.

Em pesquisa sobre materiais didáticos impressos e/ou digitais específicos de Música para o ensino médio, foi encontrado apenas um livro que abarcasse os três anos que compõe esse nível de formação (VITORINO; ALVES, 2013). Ao analisar a realidade de outros países, como Espanha e Estados Unidos, onde a Música está consolidada no currículo escolar como disciplina obrigatória, verificou-se a existência de uma ampla variedade de publicações direcionadas ao ensino médio, o que possibilita aos professores e aos centros educativos o direito de escolha em função de critérios específicos que lhes permitam selecionar o material mais adequado à sua realidade. Portanto, acredita-se que a criação e a implementação de políticas públicas efetivas que compreendam a Música como uma disciplina (e não apenas como conteúdo) incentivarão o surgimento de um maior número de materiais didáticos específicos dessa linguagem para o ensino médio.

Atrelado a isso (e relacionado às ações práticas), a inserção de profissionais licenciados em Música por meio de concurso e/ou seletivo nas escolas tende a transformar a tão criticada polivalência no ensino da Arte em um trabalho interdisciplinar entre as linguagens, respeitando assim a formação oferecida pelas universidades e atendendo também às orientações presentes nos Parâmetros Curriculares Nacionais (PCN). Com isso, espera-se obter uma educação musical de melhor qualidade, mais consciente, em conformidade com as bases epistemológicas da área de Música e que atenda de maneira eficaz às demandas sociais dos diferentes contextos brasileiros.

\footnotetext{
${ }^{3}$ Educação a distância.

4 O PARFOR tem como objetivo "induzir e fomentar a oferta de educação superior, gratuita e de qualidade, para professores em exercício na rede pública de educação básica” (CAPES, 2016).
} 


\section{3 | MÚSICA NO ENSINO MÉDIO E AS DIRETRIZES CURRICULARES DA SEDUC-MA}

Partindo da premissa levantada nesse estudo - a inserção da música enquanto disciplina do ensino médio - torna-se necessário pensar um currículo que tenha em seu fundamento não a formação de músicos profissionais, mas sim "capacitar os estudantes a humanizarem-se melhor como cidadãos inteligentes, sensíveis, estéticos, reflexivos, criativos" (BRASIL, 2000, p. 50), a partir de vivências ricas e significativas da linguagem musical, ampliando assim sua cultura geral, formando-o de modo integral. Com base nessa perspectiva, algumas questões são levantadas constantemente por especialistas da área: Quais conteúdos musicais deveriam ser ensinados nas escolas? Qual seria o currículo ideal que atenderia às necessidades da educação básica? O que o aluno gostaria de aprender sobre o universo musical?

Sobre essas questões, Kleber (2003) aponta como vieses de discussão dois importantes conceitos presentes em diversos documentos educacionais: a interdisciplinaridade e a diversidade cultural. Sobre o primeiro conceito, Andrade (1998, p. 95) esclarece que a interdisciplinaridade é uma concepção do saber que tem como base "a interdependência, a interação, a comunicação existente entre as disciplinas e buscando a integração do conhecimento num todo harmônico e significativo". Pode-se perceber na fala da autora o trabalho dependente e integrado entre diferentes disciplinas, entendendo-as como igualmente importantes para o desenvolvimento do conhecimento. De acordo com Pereira (2000), a interdisciplinaridade não pode ser confundida com a polivalência, uma vez que são respeitados o conhecimento específico (disciplinar) e o papel de cada profissional. Assim sendo, no trabalho interdisciplinar é necessário que o professor leve em consideração o corpus selecionado para a disciplina e sua relação com outros três aspectos: "1) com a área em que se insere a disciplina; 2) da área com as outras [...] áreas propostas no PCN; 3) da área com a realidade local" (BRASIL, 2002, p. 28).

Fundamentado nesses aportes, podemos refletir sobre o espaço que a Música vem recebendo dentro das escolas de ensino médio nesses últimos anos. Em primeiro lugar, como já discutido anteriormente, os adolescentes natu- ralmente escutam, fazem, falam e pensam sobre música. Vários estudos apontam que mesmo não fazendo parte oficialmente do currículo escolar, a música está presente nas práticas informais dos adolescentes, servindo a diferentes objetivos: como expressão de sentimentos, para aceita-ção e coesão grupal, como expressão da identidade pessoal, etc. (NORTH; HARGREAVES, 2008; QUADROS JR., 2017).

Em segundo lugar, a música por diversas vezes é empregada como instrumento de facilitação didática por professores de outras disciplinas (CAVALCANTI; LINS, 2010; COSTA, 2003). Um exemplo disso são as canções ou paródias criadas para assimilação de fórmulas matemáticas, leis da física, compostos químicos, etc. Esse tipo de trabalho não serve aos princípios da interdisciplinaridade, uma vez que não acontece a integração entre as áreas, mas ocorre uma sobreposição ou um usufruto em função de um objetivo de aprendizagem. Ademais, não atende também aos preceitos epistemológicos e aos objetivos defendidos pela área da Educação Musical e previstos nos documentos educacionais oficiais. Assim sendo, buscar formas de trabalho conjunto onde ocorra efetivamente o diálogo e a integração entre a Música e as diferentes áreas do conhecimento ganha importância na medida em que se vislumbram melhorias para a educação de nível médio. Analisar a letra de uma canção não faz parte do conteúdo da área de Música, mas sim de línguas (Português, Inglês, Espanhol, etc.) ou mesmo de Literatura. Por outro lado, um trabalho conjunto com essas áreas onde se proponha o desenvolvimento de atividades de apreciação, criação, execução e/ou improvisação musicais tornará a proposta verdadeiramente interdisciplinar.

Uma terceira ocorrência da presença da Música no ensino médio é por meio de projetos direcionados à prática musical, que ocorrem muitas vezes via programas como "Mais Educação", 
"Escola Aberta", "Ensino Médio Inovador" e "Mais Cultura nas Escolas" (PENNA, 2011). As propostas desses projetos visam o desenvolvimento musical dos participantes e estão abertas a qualquer estudante da escola que tenha interesse em aprender música.

Sobre isso, é importante refletir sobre dois aspectos essenciais e estruturantes dessas propostas. O primeiro deles diz respeito ao propósito. Como se tratam de projetos, é natural desconsiderá-las como uma ação que visa atender às determinações da atual LDB, uma vez que não consegue abarcar todos os alunos das escolas e nem tampouco faz parte do currículo oficial. $\mathrm{O}$ segundo aspecto, por sua vez, se refere aos profissionais que atuam a frente desses projetos. Não existe qualquer exigência legal no que diz respeito à necessidade de capacitação formal e específica relacionada ao trabalho que será desenvolvido, isto é, um professor de violão não precisa ter uma formação técnica, superior ou qualquer certificação profissional em Música ou em seu instrumento para atuar nesse mercado. Por um lado, a ausência dessa exigência traz benefícios ao possibilitar a participação de membros da cultura popular ou mesmo de músicos práticos a frente desses trabalhos, inserindo-os no cenário da educação formal. Por outro, ela agrega uma grande margem de incerteza a esses projetos no tocante a elementos vitais do processo pedagógico, tais como objetivos, matriz de conteúdos, planejamento, metodologias, métodos de avaliação e resultados, sem mencionar as competências idiossincráticas do campo artístico que ultrapassam a mera reprodução de canções. Baseado no panorama acima apresentado, pode-se afirmar que muitos avanços ainda são necessários para que seja possível concretizar propostas interdisciplinares que envolvam música e, para tanto, faz-se importante a presença de profissionais capacitados que contribuam para a construção dessas propostas.

Partindo para a discussão sobre o segundo conceito evidenciado por Kléber (2003), é importante salientar que as Orientações Educacionais Complementares aos Parâmetros Curriculares Nacionais (PCN+ Ensino Médio) vincula os termos diversidade e singularidade culturais como "conceitos fundamentais para a pesquisa, o reconhecimento e a análise dos fatores responsáveis pela diversidade e pela individualidade de manifestações artísticas e concepções estéticas de diferentes culturas, épocas e regiões" (BRASIL, 2002, p. 188). Historicamente, o ensino de música sempre se baseou nos conteúdos de tradições ocidentais com respeito aos aspectos musicais formais (melodia, harmonia, ritmo, etc.). Os estudos de antropólogos e etnomusicólogos proporcionaram com o tempo uma ampliação dessa visão e consequentemente do próprio conceito de música. Com isso, novas práticas foram incorporadas aos conteúdos tradicionalmente estabelecidos, ganhando espaço as culturas africana e oriental, além de se desmitificar a ideia de que apenas uma pequena parcela da população mundial - aqueles que possuíam o dom divino - poderiam aprender música (SCHROEDER, 2004). A quebra desses paradigmas veio fortalecer e valorizar a diversidade cultural como um dos pilares para a educação desse novo milênio, sendo considerada pelo $\mathrm{PCN}+$ Ensino Médio como fonte de interlocução, reflexão e respeito às diferenças.

A Declaração Universal sobre a Diversidade Cultural (UNESCO, 2002, p. 2) entende que a valorização e o respeito à diversidade cultural só é possível a partir do emprego de diferentes ações que incentivem o pluralismo cultural. Segundo esse documento, "o pluralismo cultural constitui a resposta política à realidade da diversidade cultural." Para tanto, a UNESCO (2002, p. 6) estabelece como um dos objetivos "promover, por meio da educação, uma tomada de consciência do valor positivo da diversidade cultural e aperfeiçoar, com esse fim, tanto a formulação dos programas escolares como a formação dos docentes."

Entendendo a Arte (e especialmente a Música) com uma das áreas do conhecimento de maior propensão ao desenvolvimento de propostas atreladas às determinações da UNESCO acerca da diversidade cultural, e também ressaltando o seu grande potencial interdisciplinar - o que é forte- 
mente explorado nos documentos legais da educação brasileira - partimos para uma análise das Diretrizes Curriculares da Secretaria de Estado da Educação do Maranhão (SEDUC-MA). Esse documento fornece as orientações necessárias para o planejamento curricular das escolas, determinando as matrizes curriculares que "expressam, de modo claro e objetivo, a quantidade e a qualidade do que deve ser aprendido e do que deve ser ensinado nas escolas, possibilitando com isso que o trabalho pedagógico se faça de forma interdisciplinar e transversal" (MARANHÃO, 2014, p. 37). Desse modo, essa análise tem como objetivo identificar os conteúdos musicais previstos para a disciplina Arte e contemplados nas Diretrizes Curriculares para o Ensino Médio.

Em conformidade com os documentos nacionais, essa disciplina está inserida na área 'Linguagem, Códigos e suas Tecnologias', devendo ser realizada a partir de três vértices: criação/ produção, apreciação estética e crítica, e contextualização histórica. Se baseia na percepção, no incentivo à criatividade, na articulação da "cognição, [da] memória e [da] sensibilidade, favorecendo o envolvimento do educando com a produção, a leitura e a compreensão crítica do fato artístico, promovendo o pensamento por meio dos sentidos" (MARANHÃO, 2014, p. 42).

Existem quatro linguagens artísticas vigentes no currículo: Artes Visuais, Teatro, Música e Dança. Os conteúdos para cada linguagem são organizados em três grupos: elementos formais, fundamentos compositivos, e movimentos e períodos. Em si tratando da proposta de aprendizagem, do conteúdo, da metodologia e da avaliação musicais para o Ensino Médio, o documento determina:

Tabela 1 - Aprendizagem, conteúdos, metodologia e avaliação musicais presentes nas Diretrizes Curriculares de Arte para o Ensino Médio da SEDUC-MA

\begin{tabular}{|c|c|c|c|}
\hline $\begin{array}{c}\text { O que deverá ser } \\
\text { aprendido }\end{array}$ & $\begin{array}{c}\text { O que deverá ser } \\
\text { ensinado }\end{array}$ & $\begin{array}{c}\text { Como deverá ser } \\
\text { ensinado }\end{array}$ & $\begin{array}{c}\text { O que deverá ser } \\
\text { avaliado }\end{array}$ \\
\hline $\begin{array}{l}\text { - Identificar a importância } \\
\text { da música nos contextos } \\
\text { cultural, histórico e social; } \\
\text { - Identificar os elementos } \\
\text { pertencentes à linguagem } \\
\text { da música de forma con- } \\
\text { textualizada e prática; } \\
\text { - Reconhecer os diferentes } \\
\text { sons, estilos e gêneros } \\
\text { musicais; } \\
\text { - Desenvolver habilidades } \\
\text { de elaborar registros } \\
\text { pessoais para a siste- } \\
\text { matização das experiên- } \\
\text { cias vivenciadas; } \\
\text { f Realizar leitura e } \\
\text { fruição de trabalhos musi- } \\
\text { cais produzidos na esco- } \\
\text { la e fora dela, por grupos } \\
\text { amadores ou profissionais. }\end{array}$ & $\begin{array}{l}\text { - História da Música Mara- } \\
\text { nhense; } \\
\text { - Movimentos musicais do } \\
\text { século XX; } \\
\text { - Atributos do som; } \\
\text { - Música e multiculturalis- } \\
\text { mo; } \\
\text { • Criação, execução e } \\
\text { apreciação musical. }\end{array}$ & $\begin{array}{l}\text { - Exercite, a partir da } \\
\text { história da música, a apre- } \\
\text { ciação musical; } \\
\text { - Realize aulas teóricas; } \\
\text { - Proponha ações para } \\
\text { interferir, transformar a } \\
\text { paisagem sonora utilizan- } \\
\text { do os estudos da lingua- } \\
\text { gem da música. }\end{array}$ & $\begin{array}{l}\text { - O reconhecimento das } \\
\text { características dos sons; } \\
\text { - Conhecimento de } \\
\text { autores, peças, estilos e } \\
\text { gêneros musicais; } \\
\text { - A criação, execução e } \\
\text { apreciação musical; } \\
\text { - A participação ativa em } \\
\text { todas as atividades. }\end{array}$ \\
\hline
\end{tabular}

Fonte: Diretrizes Curriculares. Área do Conhecimento: Linguagens, códigos e suas tecnologias - Disciplina: Arte Ensino Médio (MARANHÃO, 2014, p. 45). 
Pode-se verificar que as Diretrizes Curriculares da SEDUC-MA possuem consonância com o que é preconizado em documentos oficiais como a LDB, o PCN, o PCN+ Ensino Médio e as Orientações Curriculares para o Ensino Médio (OCEM) com relação ao campo musical. Assim, observa-se no quadro acima que o trabalho do professor deve contemplar atividades de apreciação, criação, execução e história da música, elementos considerados por Swanwick (2003) como os pilares para o processo pedagógico musical contemporâneo, merecendo destaque os conteúdos 'história da música maranhense' e 'paisagem sonora'. Por outro lado, verifica-se a ausência de conteúdos atuais como percussão corporal ou construção de instrumentos musicais alternativos, bem como indicação sobre a utilização da tecnologia no desenvolvimento de atividades musicais.

Analisando a partir dos dois elementos principais estabelecidos para esse trabalho, diversidade cultural e interdisciplinaridade, observa-se que houve preocupação da SEDUC-MA em valorizar a cultura local e o multiculturalismo. Outrossim, a interdisciplinaridade é tratada durante todo o documento como um fator determinante para todas as áreas do conhecimento, mas não aparece em nenhum momento nas orientações específicas do componente Arte.

A partir do exposto, passamos à apresentação da parte empírica do projeto "Lei no 11.769/2008: plano de ações para a inserção da Música em escolas públicas de ensino médio no Maranhão", que contou com o financiamento da Fundação de Amparo à Pesquisa e ao Desenvolvimento Científico e Tecnológico do Maranhão (FAPEMA) a partir dos editais 'Apoio a Cooperações Internacionais (APCINTER)' e 'Universidade de Todos Nós (UTN)'. A pesquisa teve como objetivo geral elaborar um plano de ações para a inserção efetiva da música em escolas de ensino médio da rede Estadual de Educação do Maranhão, atendendo às exigências da Lei no 11.769/2008, com base em experiências de sucesso ocorridas no Brasil, na Europa e na América do Norte, mas que valorizasse as características específicas do contexto local.

Com relação aos objetivos específicos, se pretendeu:

a) Analisar programas curriculares de ensino musical desenvolvidos no ensino médio no Brasil, na América do Norte e na Europa;

b) Elaborar materiais didáticos para o ensino da música em conformidade com as orientações legais específicas para o ensino médic;

c) Desenvolver uma proposta curricular de ensino da música adequada às características idiossincráticas do Maranhão;

d) Promover ações extracurriculares de vivências musicais a partir de grupos musicais (bandas, coros, etc.).

\section{4 | METODOLOGIA}

Esse estudo adotou uma abordagem mista, uma vez que congrega elementos da abordagem quantitativa com outros de cunho qualitativo (SILVA; MENEZES, 2005), utilizando um desenho de pesquisa quase-experimental (WHITE; SABARWAL, 2014), envolvendo grupo controle e experimental para os quais foram aplicados três (raciocínios abstrato, numérico e verbal) dos cinco testes que compõem a Bateria de Provas de Raciocínio (BPR-5) (ALMEIDA; PRIMI, 2000), bem como o Social and Emotional or Non-cognitive Nationwide Assessment (SENNA) (SANTOS; PRIMI, 2014), para avaliação de competências socioemocionais. Por razões de extensão, esse trabalho terá como foco a explanação acerca da proposta pedagógica desenvolvida nesse experimento.

Com base em pesquisa bibliográfica, na análise dos documentos legais relacionados ao ensino médio e em pesquisa prévia realizada com professores da disciplina Arte de escolas públicas de ensino médio, constatou-se a ausência do conteúdo/disciplina Música no currículo escolar e na prática docente desenvolvida nesse nível educacional em São Luís/MA. Apoiado nesse diagnóstico, 
optou-se por elaborar um plano de ações que fomentasse a implementação da Música como disciplina e como atividade extracurricular para o ensino médio.

A elaboração desse plano de ações teve como fundamento o levantamento bibliográfico acerca de propostas pedagógico-musicais desenvolvidas no ensino médio em diversos países, bem como visitas in loco em escolas públicas na Espanha e nos Estados Unidos, o que permitiu conhecer e adquirir alguns materiais didáticos utilizados nas aulas. A escolha desses dois países teve como motivação o fato deles possuírem a Música como disciplina obrigatória no currículo oficial há várias anos.

Um segundo momento do estudo foi direcionado à pesquisa bibliográfica e documental para a elaboração da proposta e dos materiais didáticos a serem implementados, tendo como esteio diversos livros didáticos nacionais e internacionais, bem como autores da área de Educação Musical e de documentos legais que norteiam e legitimam o ensino médio (BRASIL, 1996, 2000, 2002, 2006; MARANHÃO, 2014). A partir disso, optou-se pela aquisição de materiais didáticos da Espanha, dos Estados Unidos e do Brasil, além de coleta de materiais e vídeos disponíveis na internet. Sobre isso, vale ressaltar que são praticamente inexistentes no Brasil livros e materiais didáticos destinados ao ensino médio que versam sobre Música, suportando ainda mais a necessidade de realização desse estudo.

Como resultado dessa etapa, foram elaborados seis blocos de conteúdos para o material didático a ser utilizado na pesquisa, a saber: 1) Conceitos Gerais; 2) Elementos Básicos da Música; 3) História da Música; 4) Música Urbana; 5) Música no Mundo; 6) Música e Tecnologia. Em função do tempo destinado ao trabalho de campo, dos recursos da SEDUC-MA disponíveis para a impressão e reprodução do livro didático, e das orientações estabelecidas por essa Secretaria nas Diretrizes Curriculares de Arte para o ensino médio, decidiu-se pela escolha dos blocos 'Conceitos Gerais' e 'Elementos Básicos da Música'. Finalmente, o material didático empregado na pesquisa foi composto por um livro didático, um caderno de atividades, bem com de um CD e um DVD contendo os exemplos audiovisuais dos conteúdos e das atividades propostas.

Figura 1 - Materiais didáticos implementados na pesquisa (livro e cadernos de atividades)


Fonte: Materiais da pesquisa. 
O terceiro momento do estudo esteve relacionado à pesquisa de campo propriamente dita, em que foram contempladas dez escolas públicas de ensino médio de São Luís-MA. Dessas escolas, foi selecionada uma turma de cada série que compõe esse nível escolar $\left(1^{\circ}, 2^{\circ}\right.$ e $3^{\circ}$ anos). A seleção das escolas ficou a cargo da SEDUC-MA e a escolhas das turmas que participariam do estudo ficou sob responsabilidade dos gestores de cada centro educativo.

O experimento foi desenvolvido abarcando duas vertentes distintas: 1) música enquanto disciplina; 2) música como atividade extracurricular. As aulas desenvolvidas na disciplina Música possuíam um caráter teórico-prático e foram inseridas na grade curricular oficial das turmas participantes, com carga horária de duas horas semanais, abarcando um público aproximado de 1000 alunos. A organização e a oferta dessa disciplina na grade curricular foi de responsabilidade de cada escola. Assim, algumas decidiram pelo formato de aulas germinadas (dois horários em sequência) e outras optaram pela oferta em dois momentos distintos. A contratação dos professores ficou a cargo da SEDUC-MA, assim como a impressão do material didático utilizado.

As atividades extracurriculares, por sua vez, funcionaram no contra-turno das escolas participantes, sendo acessíveis também aos alunos que por ventura não participassem da disciplina Música. Possuía carga horária de três horas semanais e contemplou aproximadamente 300 alunos em cinco modalidades: canto coral, flauta doce, fanfarra, banda musical e violão. A contratação dos professores e a compra de parte dos instrumentos musicais utilizados foi obtido através dos editais "Apoio a Cooperação Internacional" e "Universidade de Todos Nós", ambos da Fundação de Amparo à Pesquisa e ao Desenvolvimento Científico e Tecnológico do Maranhão (FAPEMA).

Para a coleta de dados, foram utilizados diferentes instrumentos, a saber:

Questionário diagnóstico e de identificação: Composto por itens de identificação (escola, série, turma, turno, idade e sexo) e por perguntas relacionadas ao conhecimento e vivência musical;

Questionário de satisfação: Composto por 2 sessões de perguntas. Na primeira, o estudante deveria avaliar o seu nível de satisfação com diversos aspectos relacionados à experiência didático-musical vivenciada. Para isso, foi empregada uma escala tipo Likert de 5 pontos, variando entre muito insatisfeito a muito satisfeito. A segunda sessão solicitou a avaliação dos alunos sobre aspectos mais gerais da experiência;

Relatório semanal dos instrutores e dos professores;

Encontros semanais para acompanhamento das atividades e reavaliação/adequação da proposta;

Relatório final dos instrutores e dos professores.

Por razões de extensão, esse trabalho se aterá ao relato do processo das aulas da disciplina Música e aos itens objetivos do questionário de satisfação respondido pelos participantes, dados que serão apresentados a continuação.

\subsection{Música como disciplina: relato sobre as aulas}

A parte empírica dessa experiência teve uma carga horária total de 40 horas/aula e contou com a colaboração dos gestores de cada escola na organização das turmas e dos horários para o desenvolvimento da pesquisa. Os conteúdos estabelecidos para as aulas tiveram como base tanto aspectos específicos da linguagem musical, como também temas que faziam parte do cotidiano dos alunos e que estabeleciam relação com a música, sessão que teve como fundamento principal a interdisciplinaridade. Assim, foi possível trabalhar assuntos como 'Eco e ressonâncias' (fazendo relação com a Física), 'Música e homem' (Sociologia e Antropologia), 'Saúde vocal' (Biologia), métrica (Matemática), andamento (Dança), dentre outros. Dessa maneira, pode-se observar no quadro abaixo todos os assuntos que compuseram o conteúdo trabalhado durante as aulas. 
MÚSICA NA ESCOLA | João F. S. de Quadros Júnior et. al.

Tabela 2 - Materiais didáticos implementados na pesquisa (livro e cadernos didáticos)

\begin{tabular}{cc}
\hline Conceitos gerais & Elementos básicos da música \\
\hline A Origem do Som & Características da música e do som \\
Parâmetros do Som & Notas musicais / Notação musical \\
O Ruído & Figuras musicais / Métrica \\
O Silêncio & Andamento/ Percussão Corporal \\
Eco e Ressonâncias & Textura Melódica / Forma e Estrutura Musicais \\
Música e Homem & Elementos de Expressão \\
Fontes Sonoras & Intervalos / Escalas / Harmonia \\
A Voz Humana & Tonalidades e Cadências \\
Saúde Vocal & Roteiro para Análise Musical
\end{tabular}

Fonte: Dados da pesquisa.

Antes do início das aulas, foi solicitado às escolas que reservassem um dia para a aplicação do questionário diagnóstico nas turmas participantes, o que ajudaria na tomada de algumas decisões importantes para a pesquisa. Infelizmente, não foi possível fazer a aplicação desse questionário a todos os alunos, seja por dificuldades de organização da escola referente ao horário de aplicação do teste ou mesmo em virtude da ausência de parte dos estudantes na aula no momento da coleta de dados. Ainda assim, essa coleta conseguiu contemplar 468 alunos (quase metade do total de participantes) de 5 das 10 escolas atendidas, gerando informações importantes para o estudo, tais como:

a) $18,9 \%$ dos participantes já haviam participado de aulas de Música anteriormente (seja no ensino formal ou não-formal);

b) $96,3 \%$ afirmaram escutar música frequentemente;

c) $87,7 \%$ dos alunos possuíam celular com acesso a Internet, sendo que $64,7 \%$ tinham Internet em casa;

d) 90,6\% dos participantes declararam ser favoráveis à inclusão da Música como disciplina no currículo escolar, enquanto que 9,4\% afirmaram ser contrários.

Com base nessas informações, foi possível confirmar a hipótese de que a música efetivamente fazia parte da vida daqueles estudantes e que a proposição desse estudo possuía ressonância nos anseios dos participantes ao observarmos a elevada frequência de escuta musical constatada e sobretudo a quase totalitária aprovação dos discentes sobre a inclusão da Música como disciplina do currículo escolar.

Por outro lado (e de maneira surpreendente), avaliamos que a proposta de utilização do CD e do DVD como recursos audiovisuais para acesso aos exemplos presentes no material didático não era a opção mais eficaz, levando-se em consideração que quase a totalidade dos alunos participantes possuíam celulares com acesso à Internet. Dessa forma, optou-se por favorecer o acesso aos exemplos audiovisuais via Youtube (plataforma de onde os exemplos foram extraídos) ou mesmo transmitidos por bluetooth ou grupos de Whatsapp. Por último, essa informação garantiu também a manutenção da proposta inicial de utilização de aplicativos de celular para o estudo musical, uma ação que visava amenizar as recorrentes reclamações dos professores sobre o uso indevido desses equipamentos em sala de aula, empregando-os para fins pedagógicos.

Antes do início das aulas, foi realizada uma capacitação pedagógica com a equipe de professores que atuaria na pesquisa, momento em que os mesmos tiveram acesso ao material didático, havendo também a apresentação da proposta de trabalho, dos objetivos, do planejamento didático, 
MÚSICA NA ESCOLA | João F. S. de Quadros Júnior et. al.

dos aplicativos que seriam utilizados, da metodologia proposta, dos instrumentos de coleta de informações, etc. Essa capacitação teve duração de 15 horas, divididas em 2 momentos, e foi extremamente importante para que o professor pudesse compreender o direcionamento pensado pela coordenação do estudo e colaborar para o desenvolvimento do trabalho.

A cada aula lecionada, os professores deveriam preencher digitalmente um relatório específico para cada turma, modelo padrão elaborado pela coordenação da pesquisa, composto por itens objetivos e dissertativos, em que os docentes indicavam o conteúdo lecionado, a utilização ou não de recursos didáticos, de exemplos audiovisuais, de exercícios do Caderno de Atividades e de atividades e exemplos audiovisuais não contemplados no material didático, avaliando ao final o comportamento e a participação da turma, bem como a sua auto-avaliação sobre a aula lecionada.

As diferentes realidades das escolas fizeram com que a dinâmica da pesquisa sofresse adaptações para que pudessem ser aceitas e compreendidas da melhor maneira possível pelos estudantes. A maior parte das escolas participantes estava localizada em áreas de grande vulnerabilidade social, com elevados índices de violência e forte presença de gangues ou facções, havendo inclusive diversos discentes que integravam tais grupos. Como exemplo desse cenário, vale citar que em uma das escolas atendidas pelo projeto ocorreu o assassinato de uma estudante ao sair da aula em virtude de briga de facções rivais. Por não conhecerem aquela realidade, tal situação oferecia aos professores de Música grande intranquilidade para o desenvolvimento do seu trabalho, não apenas em sala de aula, mas também no translado até a escola, ocorrendo por vezes assaltos aos docentes antes e/ou depois das atividades. Mediante esses acontecimentos, foram realizadas reuniões com os gestores escolares para se buscar medidas que amenizassem os riscos para os docentes. Cada gestor optou por uma solução diferente (como a reorganização dos horários para que os docentes pudessem pegar caronas com os gestores, aumento da segurança na escola, instalação de câmeras dentro e no entorno das instituições, etc.) e conseguiram coibir a situação de insegurança.

Outra questão que chamou bastante atenção foi a organização de cada escola. Ao contrário de outras realidades, cada instituição adaptava o seu horário (e consequentemente a temporalização das aulas) de acordo com a dinâmica da comunidade escolar. Havia centros educativos em que a aula durava 45 minutos, outros 40 , e até mesmo aqueles em que antes do recreio as aulas duravam mais tempo do que aquelas após o intervalo. Essa dinâmica não havia sido informada com antecedência à coordenação da pesquisa, o que levou à necessidade de adaptação das temporalizações dos conteúdos previamente estabelecidos.

Ainda sobre o item organização, foram verificadas diferenças entre o calendário anual previsto pela SEDUC-MA e o que realmente foi colocado em prática pelas escolas. Como havia ocorrido uma greve de professores no ano de 2014, o calendário informado pela SEDUC-MA indicava que as aulas do ano letivo de 2015 seriam finalizadas no mês de fevereiro de 2016. Entretanto, a maior parte das escolas participantes no estudo encerraram as atividades antes do Natal de 2015, sem informação prévia à coordenação do estudo, prejudicando assim a realização de 4 aulas do projeto. Isso também acabou prejudicando (parcialmente) a aplicação dos questionários de satisfação, o que será tratado em outra sessão.

Por último, verificou-se grande disparidade no quesito infraestrutura quando comparados os diferentes centros educativos participantes. Havia escola equipada com laboratório de informática, Internet sem fio (disponível aos alunos), salas de aula com ar-condicionado, biblioteca ampla e com variedade de livros, data-show, equipamento de som, dentre outros. Por outro lado, nos deparamos com escolas em que faltava porta nas salas de aula (dificultando bastante o desenvolvimento sobretudo de conteúdos relacionados à apreciação musical em que era necessário empregar um maior potencial de concentração), não havia água para beber, grande parte dos ventiladores estavam quebrados, a sala de informática e a biblioteca não estavam disponíveis para 
utilização dos alunos, etc. Toda essa diversidade relatada acima acabou por influenciar diretamente o desenvolvimento do cronograma das atividades e consequentemente no resultado da pesquisa.

Como uma forma de acompanhar o andamento do projeto e de buscar soluções para eventualidades que surgissem (como as situações mencionadas anteriormente), a equipe docente e a coordenação da pesquisa se encontravam semanalmente para compartilhar as experiências vivenciadas durante as aulas, avaliar a receptividade dos alunos com relação ao projeto, o processo de aprendizagem dos conteúdos, as dificuldades encontradas dentro e fora da sala de aula, etc. Logo após o compartilhamento das experiências tinha início um momento de orientação pedagógica sobre o conteúdo que seria lecionado na semana seguinte, sendo indicadas também as atividades que deveriam ser aplicadas aos alunos. Nesse momento ocorria o treinamento acerca de algum aplicativo que seria utilizado ou mesmo sobre as atividades pedagógicas, ocorrendo por vezes simulações de micro-aulas para auxiliar aspectos específicos necessários para a compreensão dos conteúdos.

Apesar de todo o acompanhamento, planejamento e capacitação dos professores, infelizmente não foi possível vencer todo o conteúdo previsto no quadro 1. Além das dificuldades mencionadas anteriormente, duas escolas acabaram entrando em greve por 20 dias durante o período da experiência, reivindicando a contratação de pessoal para fazer a vigilância das instituições. Dessa maneira, os conteúdos escalas, harmonia, tonalidades e cadências não foram lecionados.

Para avaliar o aprendizado dos estudantes, levou-se em consideração: 1) os exercícios presentes no Caderno de Atividades; 2) uma prova objetiva acerca do conteúdo lecionado; 3) os relatórios semanais dos professores. Baseado nesses dados, é possível afirmar que os estudantes participantes assimilaram bem os conteúdos lecionados, demonstrando maior dificuldade nos conteúdos relacionados aos elementos da linguagem musical, algo bastante natural, uma vez que cifras, partituras, notação musical, dentre outros códigos musicais, não faziam parte do cotidiano desses estudantes, necessitando assim um prolongamento dos estudos sobre esses assuntos.

Outrossim, observou-se que as escolas que demonstraram maior organização e que possuíam melhor infraestrutura obtiveram os melhores resultados de aprendizagem, possivelmente por terem conseguido receber o conteúdo em conformidade com o planejamento do projeto. Dessa maneira, é importante que o poder público (representado aqui pela SEDUC-MA) garanta as condições necessárias para que as escolas possam cumprir efetivamente as suas programações pedagógicas (infraestrutura adequada, quadro completo de professores desde o primeiro dia letivo, fornecimento de água e luz, segurança, alimentação, etc.), possibilitando o tão sonhado avanço na educação desse país.

\subsection{Questionário de satisfação}

Segundo Bruner (1966), toda atividade que envolve ensino-aprendizagem formal ou informal depende diretamente do nível de implicação do aprendiz nesta atividade, ou seja, cada pessoa só aprenderá o que realmente deseja aprender. Nessa perspectiva, a satisfação atua como um reforço positivo, promovendo a motivação intrínseca necessária para que o sujeito continue participando da atividade (RIFE et al., 2001). Assim sendo, utilizar um questionário de satisfação como método de avaliação da intervenção pedagógica proposta se mostrou adequado. Para tanto, foi solicitado aos estudantes participantes que contestassem a um questionário composto por 10 perguntas objetivas que avaliavam o nível de satisfação com diferentes aspectos da vivência pedagógica, utilizando para isso uma escala (tipo Likert) que variava entre muito insatisfeito (1) a muito satisfeito (5). Essa avaliação levou em consideração fatores relacionados à proposta pedagógica e fatores de cunho individual: 
MÚSICA NA ESCOLA | João F. S. de Quadros Júnior et. al.

Tabela 3 - Fatores de avaliação para o questionário de satisfação

\begin{tabular}{|c|c|}
\hline Fatores da Proposta & Fatores Individuais \\
\hline Didática/Metodologia do professor & Desenvolvimento musical individual \\
Conteúdo estudado & Desenvolvimento musical da turma \\
Atividades desenvolvidas & Comportamento pessoal durante as aulas \\
Material didático & Comportamento da turma durante as aulas \\
Exemplos audiovisuais & \\
\hline \multicolumn{2}{|c|}{ Satisfação geral com relação à proposta desenvolvida } \\
\hline
\end{tabular}

Fonte: Dados da pesquisa.

Além dessas, outras duas questões que fizeram parte do questionário solicitavam que os alunos determinassem uma nota de 0 (péssimo) a 10 (excelente) para a experiência vivenciada e que eles opinassem sobre a inclusão da Música como disciplina obrigatória do currículo escolar.

Semelhante ao ocorrido na etapa de diagnóstico, nem todos os alunos participantes do projeto quiseram ou puderam responder ao questionário de satisfação, seja por não estarem presentes na aula no momento da aplicação do instrumento, seja por se recusarem a respondê-lo. Outro fato que prejudicou a coleta de dados (como mencionado anteriormente) foi o encerramento precoce das aulas de Música em algumas escolas sem comunicação prévia pela direção e/ou SEDUC-MA, não sendo autorizada a aplicação desse questionário durante a aula de outra disciplina por estar em período de provas. Dessa maneira, o grupo de respondentes congregou 431 estudantes, de 7 das 10 escolas atendidas. Assim, será apresentada na sequência uma descrição sobre os alunos participantes nessa etapa do estudo.

Gráfico 1 - Distribuição dos participantes segundo a variável escola



Fonte: Dados da pesquisa. 
Gráfico 2 - Distribuição dos participantes segundo a variável sexo

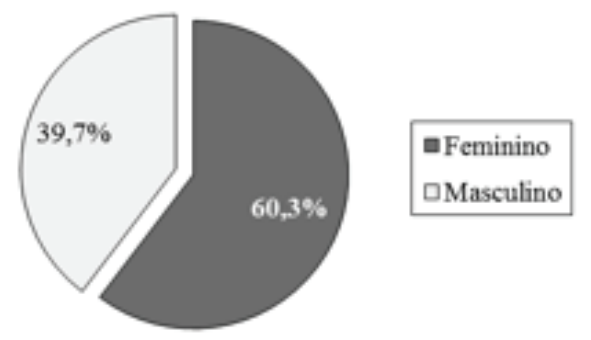

Fonte: Dados da pesquisa.

Gráfico 3 - Distribuição dos participantes segundo a variável série

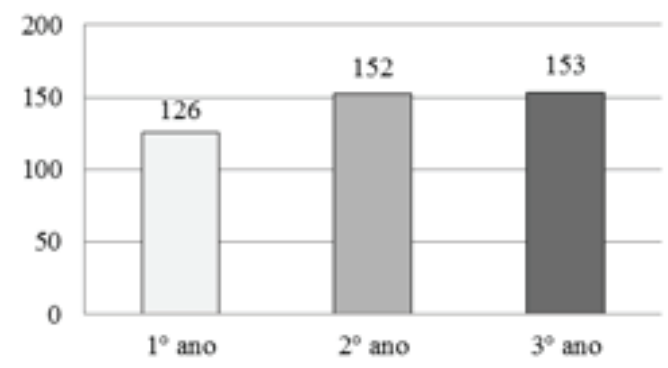

Fonte: Dados da pesquisa.

Com base nos gráficos anteriores (1 a 3), é possível verificar uma maior participação dos discentes da escola Vinícius de Morais $(24,1 \%)$, de estudantes do sexo feminino $(60,3 \%)$ em comparação com o sexo masculino $(39,7 \%)$, bem como uma menor participação de alunos do $1^{\circ}$ ano (126) em comparação com as duas outras séries $\left(2^{\circ}\right.$ ano $=152 ; 3^{\circ}$ ano $\left.=153\right)$. A continuação serão apresentados os resultados obtidos com o questionário de satisfação.

\subsection{Avaliação geral sobre o nível de satisfação dos discentes com relação à experiência vivenciada}

Tabela 4 - Estatísticos descritivos gerais sobre a avaliação dos discentes com relação à experiência vivenciada

\begin{tabular}{ccccc}
\hline \multirow{2}{*}{ Aspectos } & \multicolumn{2}{c}{$\mathbf{N}$} & \multirow{2}{*}{ Média } & \multirow{2}{*}{ Desvio Padrão } \\
\cline { 2 - 3 } & Válidos & Perdidos & & \\
\hline Didática do Professor & 429 & 2 & 4,2 & 1,03 \\
Comportamento Pessoal & 429 & 2 & 4,2 & 1,05 \\
Material Didático & 425 & 6 & 4,2 & 1,07 \\
Satisfação com as aulas de música & 428 & 3 & 4,1 & 1,08 \\
Conteúdo Estudado & 424 & 7 & 4,1 & 1,08 \\
Atividades Desenvolvidas & 426 & 5 & 4,0 & 1,11 \\
Desenvolvimento Pessoal & 423 & 8 & 3,8 & 1,14 \\
Exemplos Audiovisuais & 418 & 13 & 3,7 & 1,19 \\
Desenvolvimento da Turma & 427 & 4 & 3,5 & 1,32 \\
Comportamento da Turma & 427 & 4 & 3,3 & 1,43 \\
\hline
\end{tabular}


De modo geral, os estudantes participantes avaliaram de forma positiva todos os aspectos indicados no teste, com médias sempre superiores a 3. Como é possível verificar na tabela 1, quatro dos cinco fatores relacionados à proposta pedagógica obtiveram média superior a 4 (didática do professor, material didático, conteúdo estudado e atividades desenvolvidas), avaliação semeIhante para os itens "satisfação com as aulas de música" e "comportamento pessoal durante as aulas". Por outro lado, observa-se que a maior parte dos itens de menor pontuação estiveram relacionados aos fatores de cunho individual (desenvolvimento musical pessoal, desenvolvimento musical da turma e comportamento da turma). A diferença de avaliação entre os discentes e os docentes sobre o aspecto desenvolvimento musical converge com Nunziati (1990) ao afirmar que o roteiro de aprendizagem dos alunos não necessariamente segue a lógica estabelecida pelo professor para a disciplina. A auto-avaliação é definida pela literatura científica como uma avaliação deliberada do sujeito sobre o seu desempenho em uma dada atividade ainda durante o seu decurso, uma ação que envolve processos mentais que levam o sujeito a tomar consciência das diferentes etapas e elementos que compõe a atividade realizada (HADJI, 1997; SANTOS, 2002). Esse resultado enfatiza a necessidade de que os professores construam com seus alunos ambientes propícios ao desenvolvimento da auto-avaliação, promovendo assim uma maior autonomia do discente frente ao seu aprendizado.

Além disso, foi solicitado também que os alunos valorassem a experiência vivenciada em uma escala de 0 (péssima) a 10 (excelente), obtendo-se uma média global de 8,5. Essa avaliação atrelada às médias para os 10 itens do questionário de satisfação confirmam a aceitação e a aprovação do projeto desenvolvido.

\subsection{Opinião sobre a inclusão da música no ensino médio}

\section{Gráfico 4 - Opinião dos alunos a respeito da obrigatoriedade da música no currículo escolar}

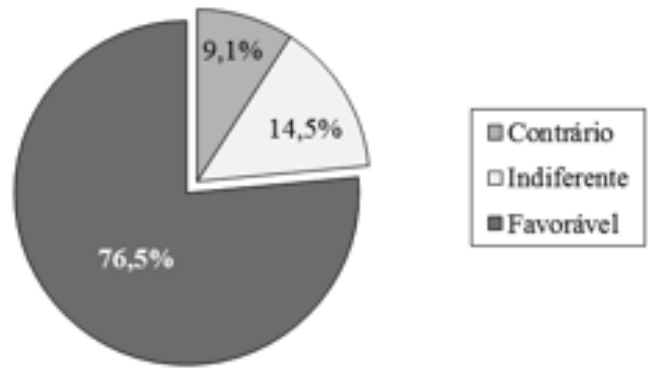

Fonte: Dados da pesquisa.

Questionados sobre sua opinião acerca da inclusão da Música enquanto disciplina curricular obrigatória, $76,5 \%$ se declararam como favoráveis, $14,5 \%$ como indiferentes e 9,1\% como contrários (gráfico 4). Para fazermos uma comparação entre esse resultado e aquele obtido na avaliação diagnóstica é necessário desconsiderar a categoria “Indiferente", uma vez que a mesma não era uma opção de resposta no primeiro questionário. Levando-se em conta apenas as categorias "Favorável" e "Contrário" (367 respostas), verificamos que 89,4\% desse total se declararam favoráveis, enquanto $10,6 \%$ afirmaram ser contrários à proposta de inclusão dessa disciplina no currículo escolar. Dessa maneira, a proximidade entre os percentuais de ambos os testes vem reforçar o grande interesse dos discentes em que a Música se torne uma disciplina obrigatória do ensino médio. 
MÚSICA NA ESCOLA | João F. S. de Quadros Júnior et. al.

\section{5 | CONSIDERAÇÕES FINAIS}

Esse estudo teve como objetivo implementar um plano de ações que fomentasse a inclusão da Música em escolas de ensino médio em São Luís/MA. Para tanto, buscamos elaborar uma proposta curricular de ensino de Música adequada à legislação e aos documentos norteadores da educação, tanto em âmbito nacional (LDB, PCN, PCN+ e OCEM) como local (Diretrizes Curriculares para o ensino médio da SEDUC-MA). Além disso, o trabalho propôs também a elaboração de materiais didáticos para o ensino de Música específicos para o ensino médio, em conformidade com o previsto nas Diretrizes Curriculares da SEDUC-MA e em consulta a materiais didáticos já existentes.

Após a análise da experiência (seja pelo relato das aulas, seja pelos dados obtidos nos questionários aplicados), é possível afirmar que a avaliação dos participantes e dos professores foi positiva, denotando a necessidade de realização de novos estudos dessa natureza que suscitem dados empíricos para fomentar a discussão acerca da real implementação da Lei n $13.278 / 16$ e das Diretrizes Nacionais para Operacionalização do Ensino de Música (BRASIL, 2016b). Dessa forma, poderemos mapear as ações que vem sendo desenvolvidas nos diferentes estados brasileiros, ampliando essa visão para cenários distantes das capitais, possibilitando assim uma reflexão profunda sobre diversos aspectos que influem na inclusão da Música no currículo escolar.

A realização desse estudo permitiu comprovar a influência de fatores como infraestrutura, quadro de professores, recursos didáticos, água, segurança, etc., no desenvolvimento da educação pública no Brasil, interferindo diretamente no processo de ensino-aprendizagem (não apenas musical) dos discentes. Assim, cabe aos órgãos governamentais que gerenciam a educação nesse país garantir as condições necessárias para o desenvolvimento do conhecimento e a formação humana desses adolescentes.

Por último, sugere-se para futuras pesquisas a verificação da influência do estudo musical no progresso educacional global dos estudantes de ensino médio, com possibilidade de ampliação para outros níveis de ensino, concebendo essa disciplina como um elemento integrado às outras áreas do conhecimento, permitindo assim a elaboração de propostas que favoreçam uma formação mais ampla, contextualizada e significativa dos e para os discentes.

Pensar a música na escola é uma batalha que envolve os interesses de diferentes segmentos educacionais, sendo muitas das vezes considerado como algo para avolumar ainda mais o atual currículo escolar, dominado pelas disciplinas que mais influem nos índices de avaliação da educação e que dominam os processos seletivos para ingresso no ensino superior. Direcionar a formação do indivíduo a partir dessa perspectiva pragmática atenua o desenvolvimento de outras valiosas características dos seres humanos, como a criatividade e as competências socioemocionais, aspectos presentes em diversos debates sobre educação nos últimos anos.

Com base nessa ótica, acreditamos que fomentar espaços e tempos para atividades e disciplinas que tenham como característica principal o desenvolvimento desses dois aspectos supracitados se torna uma prioridade para a escola do século XXI. Com isso, poder-se-á vislumbrar uma sociedade mais sensível, mais consciente e (porquê não?) mais humana. 
MÚSICA NA ESCOLA | João F. S. de Quadros Júnior et. al.

\section{REFERÊNCIAS}

ALMEIDA, L.; PRIMI, R. BPR-5: Bateria de Provas de Raciocínio. São Paulo: Casa do Psicólogo, 2000.

ANDRADE, R. M. Interdisciplinaridade: um novo paradigma curricular. In: GOULART, I. (Org.). A educação na perspectiva construtivista: reflexões de uma equipe interdisciplinar. 2. ed. Petrópolis: Ed. Vozes, 1998. p. 93-104.

BARBOSA, A. M. Arte-Educação no Brasil: realidade hoje e expectativas futuras. Estudos avançados, v. 3, n. 7, p. 170-182, 1989.

BRASIL. Lei n 9.394, de 23 de dezembro de 1996. Lei de Diretrizes e Bases da Educação Nacional. Diário Oficial da União, Brasília, DF, 23 dez. 1996.

. Lei $n^{\circ} 11.769$, de 18 de agosto de 2008. Altera a Lei $n^{\circ}$ 9.394, de 20 de dezembro de 1996, Lei de Diretrizes e Bases da Educação, para dispor sobre a obrigatoriedade do ensino da música na educação básica. Diário Oficial da União, Brasília, DF, 19 ago. 2008.

Lei $\mathrm{n}^{\circ} 13.278$, de 02 de maio de 2016. Altera o § 6 o do art. 26 da Lei no 9.394, de 20 de dezembro de 1996, que fixa as diretrizes e bases da educação nacional, referente ao ensino da arte. Diário Oficial da União, Brasília, DF, 3 maio 2016a.

Ministério da Educação. Secretaria de Educação Básica. Orientações curriculares para o ensino médio: linguagens, códigos e suas tecnologias. Brasília: MEC; SEB, 2006. v. 1.

Ministério da Educação. Secretaria de Educação Básica. PCN + ensino médio: orientações educacionais complementares aos parâmetros curriculares nacionais: linguagens, códigos e suas tecnologias. Brasília: MEC; SEB, 2002.

Ministério da Educação. Secretaria de Educação Média e Tecnológica. Parâmetros curriculares nacionais: ensino médio. Brasília: MEC; SEMTEC, 2000.

Resolução CNE/CEB n 2, de 10 de maio de 2016. Define Diretrizes Nacionais para a operacionalização do ensino de Música na Educação Básica. Diário Oficial da União, Brasília, DF, 11 maio 2016b. Seção 1, p. 42.

BRUNER, J. Uma nova teoria de aprendizagem. Tradução Norah Levy Ribeiro. 4. ed. Rio de Janeiro: Edições Bloch, 1966.

CAPES. Plano Nacional de Formação de Professores de Educação Básica - PARFOR. Brasília, DF, 2016. Disponível em: <http://www.capes.gov.br>. Acesso em: 16 jan. 2016.
CAVALCANTI, V. de S.; LINS, A. F, Musicalizando o currículo: uma proposta de ensino e aprendizagem de matemática. Espaço do Currículo, v. 3, n. 1, p. 363-379, mar./set. 2010.

COSTA, N. Canção popular e ensino da língua materna: o gênero canção nos parâmetros curriculares de língua portuguesa. Linguagem em (Dis)curso, v. 4, n. 1, p. 9-36, set. 2003.

FERNANDES, I. Brincando e aprendendo: um novo oIhar para o ensino da música. São Paulo: Editora UNESP, 2011.

FIALHO, V. Música - PARFOR: O que é? Como é? In: CONGRESSO NACIONAL DA ASSOCIAÇÃO BRASILEIRA DE EDUCAÇÃO MUSICAL, 22., 2015, Natal. Anais eletrônicos... Natal: ABEM, 2015. p. 3-12. Disponível em: <http://www.abemeducacaomusical.com. br>. Acesso em: 10 jul. 2017.

FIGUEIREDO, S.; ALBERTI, G. A música nas séries iniciais do Ensino Fundamental: orientações para seu ensino em Vitória (ES) e Distrito Federal. In: SEMINÁRIO DE INICIAÇÃO CIENTÍFICA E V JORNADA DE PESQUISA DO CEART, 19., 2009, Florianópolis. Anais eletrônicos ... Florianópolis: UDESC, 2009. p. 1-7. Disponível em: $<$ https://www.inesul.edu.br/professor/arquivos_alunos/ doc_1311627074.pdf>. Acesso em: 10 jul. 2017.

GOODSON, I. F. Currículo: teoria e história. 7. ed. Petrópolis, RJ: Vozes, 2005.

HADJI, C. L'évaluation démystifiée. Paris: ESF Éditeur, 1997.

JORDÃO, G. et al. (Coord.). A música na escola. São Paulo: Allucci \& Associados Comunicações, 2012.

KLEBER, M. Qual currículo?: pensando espaços e possibilidades. Revista da ABEM, Porto Alegre, v. 8, p. 5762, mar. 2003.

LEITE, C. A flexibilização curricular na construção de uma escola mais democrática e inclusiva. Território Educativo: Revista da Direcção Regional de Educação do Norte, Porto-Portugal, n. 7, p. 20-26, maio 2000.

LIBÂNEO, J. C. Organização e gestão da escola: teoria e prática. 5. ed. rev. ampl. Goiânia: Alternativa, 2004.

MARANHÃO. Secretaria de Estado da Educação. Diretrizes curriculares. 3. ed. São Luís: SEDUC, 2014. 107 p.

MENDES, J.; CARVALHO, V. Ações para a implementação do ensino de música na escola: uma experiência no município de Natal/RN. Revista da ABEM, n. 20, p. 118-130, 2012. 
NORTH, A. C.; HARGREAVES, D. J. (Org.). The social and applied psychology of music. Oxford: Oxford University Press, 2008.

NUNZIATI, G. Pour construire un dispositif d'évaluation formatrice. Cahiers Pedagogiques, n. 280, p. 47-62, 1990.

PACHECO, J. A. Currículo: teoria e práxis. Porto, Portugal: Porto Editora, 1996.

Escritos curriculares. São Paulo: Cortez, 2005.

PENNA, M. A dupla dimensão da política educacional e a música na escola: I - analisando a legislação e termos normativos. Revista da ABEM, Porto Alegre, v. 10, p. 19-28, 2004.

Educação musical e educação integral: a música no Programa Mais Educação. Revista da ABEM, v. 19, n. 25, p. 141-152, 2011.

PEREIRA, A. R. S. Educação agora é para a vida. Boletim do Novo Ensino Médio, Brasília, DF: MEC; SEMTEC, ano 1, n. 4, maio/jun. 2000.

QUADROS JR., J. F. S. de. Mass Media y consumo musical en estudiantes de enseñanza secundaria en Brasil. Cuadernos de Lingüística Hispánica, n. 30, 2017. Disponível em: <http://revistas.uptc.edu.co/index.php/ linguistica_hispanica/article/view/6194>. Acesso em: 16 jan. 2016.

QUADROS JR., J. F. S. de; QUILES, O. L. Música na escola: uma revisão das legislações educacionais brasileiras entre os anos 1854 e 1961. Revista Música Hodie, Goiânia, v. 12, n. 1, p. 175-190, 2012.

QUEIROZ, L. R. S. Carta ao Excelentíssimo Senador Pedro Chaves dos Santos Filho. Associação Brasileira de Educação Musical, João Pessoa, out. 2016. Disponível em: <http://abemeducacaomusical.com.br/ artsg2. asp?id=139>. Acesso em: 16 jan. 2016.

RIFE, N. A. et al. Children's satisfaction with private music lessons. Journal of Research in Music Education, v. 49, n. 1, p. 21-32, Apr. 2001.
SANTOS, D.; PRIMI, R. Desenvolvimento socioemocional e aprendizado escolar: uma proposta de mensuração para apoiar políticas públicas. Relatório sobre resultados preliminares do projeto de medição de competências socioemocionais no Rio de Janeiro. São PauIo: OCDE, SEEDUC, Instituto Ayrton Senna, 2014.

SANTOS, L. Auto-avaliação regulada: porquê, o quê e como? In: ABRANTES, P.; ARAÚJO, F. (Coord.). Avaliação das aprendizagens. Lisboa: DEB; ME, 2002. p. 75-84.

SCHROEDER, S. C. N. O músico: desconstruindo mitos. Revista da ABEM, Porto Alegre, v. 12, n. 10, p. 109118, mar. 2004.

SILVA, E. L. da; MENEZES, E. M. Metodologia da pesquisa e elaboração de dissertação. 4. ed. rev. atual. Florianópolis: UFSC, 2005.

SWANWICK, K. Ensinando música musicalmente. Tradução Alda Oliveira e Ana Cristina Tourinho. São Paulo: Moderna, 2003.

UNESCO. Declaração universal sobre a diversidade cultural. 2002. 7 p. Disponível em: <http://unesdoc.unesco.org/images/0012/001271/127160por.pdf>. Acesso em: 16 jan. 2016.

VEIGA, I. (Org.). Projeto Político-Pedagógico da escola: uma construção possível. 23. ed. Campinas, SP: Papirus, 2007.

VITORINO, L.; ALVES, Y. Música faz. Brasília: Editora HTC, 2013.

WHITE, H.; SABARWAL, S. Quasi-Experimental Design and Methods. Methodological Briefs: Impact Evaluation 8. Florência (Itália): UNICEF Office of Research, 2014.

WOLFFENBÜTTEL, C. R. A inserção da música no projeto político pedagógico: o caso da Rede Municipal de Ensino de Porto Alegre/RS. 2009. 292 f. Tese (Doutorado em Música)- Instituto de Artes, Universidade Federal do Rio Grande do Sul, Porto Alegre, 2009. 